\title{
Decrease in Driveline Infections with Change in Driveline Management Protocol
}

\author{
Saima Aslam*, Jennifer Dan, Amanda Topik, Michael Belyk, \\ Francesca Torriani, Randy Taplitz, Jorge Silva-Enciso, Denise \\ Barnard, Barry Greenberg, Jack Copeland, Victor Pretorius, Eric \\ Adler
}

University of California, San Diego, CA

* Corresponding author: saslam@ucsd.edu
Citation: Aslam, S. et al.

(2016)."Decrease in Driveline

Infections with Change in

Driveline Management Protocol"

The VAD Journal, 2. doi: http://dx.doi.org/10.13023/VAD. 2016.03

Editor-in-Chief: Maya Guglin, University of Kentucky

Received: February 9, 2016

Accepted: February 20, 2016

Published: March 3, 2016

(c) 2016 The Author(s). This is an open access article published under the terms of the Creative Commons Attribution-

NonCommercial 4.0 International License

(https://creativecommons.org/lice nses/by-nc/4.0/), which permits unrestricted non-commercial use, distribution, and reproduction in any medium, provided that the original author(s) and the publication source are credited.

Funding: Not applicable

Competing interests: Not applicable

\section{Abstract \\ Background}

Driveline infections (DLI) are a significant cause of morbidity and mortality in ventricular assist device (VAD) recipients. We compared driveline infection (DLI) rate after an institutional change in driveline management protocol.

\section{Methods}

We retrospectively reviewed records of left VAD recipients at our institution, based on driveline management. Group 1: daily driveline dressing change consisting of chlorhexidine cleansing, sterile $4 \times 4$ gauze, and use of an abdominal binder. Group 2: Dressing change every 3 days consisting of chlorhexidine cleansing, non-sterile silver-impregnated foam with overlying clear dressing, and use of a driveline anchor. Follow-up was censored at first DLI, device removal, transplant or death. Additionally, Group 1 patients' follow-up was censored when the change in protocol occurred. Statistical analysis: Student's t-test, Fisher's exact test, Kaplan-Meier curve and log-rank test.

\section{Results}

DLI occurred in $16 \%$ of 88 VAD recipients (Group $1 \mathrm{n}=24$, Group $2 \mathrm{n}=64$ ). The new driveline management protocol resulted in significantly fewer DLI in Group 2 $(6.3 \%$ vs. $41.7 \%, p<0.0001)$ 


\section{Conclusions}

An updated driveline management protocol demonstrated significant reduction in DLI at our institution. Studies evaluating the optimal approach for driveline management are needed in order to develop a standardized regimen aimed at lowering the risk of DLI.

\section{Keywords}

Ventricular assist device; driveline infection; driveline dressing; infection prevention

\section{Introduction}

Heart failure is a major cause of morbidity and mortality in the United States, where about 5.1 million people are living with heart failure; half of these patients will die within 5 years of diagnosis.(1) Ventricular assist devices (VADs) have emerged as a standard of care for patients with end-stage heart failure, both as a bridge to transplant (BTT) and as destination therapy (DT) with actuarial survival of $80 \%$ at one year and improved quality of life.(2) However, VAD use is associated with various complications, including percutaneous driveline infections (DLIs).

Overall rate of DLI in various studies ranges from 14-48\%; infections appear to be cumulative over time with increased DLI noted with greater duration of VAD support.(3-5) DLIs negatively impact recipient quality of life; potential complications include development of sepsis/ bacteremia, hospital readmission(s), pump pocket infection, re-operation, and decreased survival.(3, 4, 6) Risk factors for DLI include obesity, diabetes, younger age, trauma to the driveline site, and length of implantation.(4-6)

Currently there are no standardized protocols for the type of driveline dressing used or the frequency of change; VAD centers in the United States use a variety of protocols. (7) Current measures to decrease the rate of DLI include tunneling the driveline within the abdominal subcutaneous tissue, stabilization of the device, and use of various dressing change protocols. Stabilization of the driveline has generally been achieved with the use of abdominal binders. A recent survey of VAD coordinators among 38 US centers showed that $70 \%$ of the responding centers used a stabilization belt.(7) Several recent papers discuss alternative stabilization techniques for the driveline such as use of StatLock system with a silicone suture, Centurion Foley anchor, or Hollister tube holder instead of the abdominal binder that is easier and more comfortable for the patient to use. $(7,8)$ The same survey also noted that there was no standard for dressing change protocols in terms of agents used and the frequency of dressing changes though $60 \%$ of programs reported daily dressing changes. It is also not clear if sterile technique should be applied at each dressing change. 
We describe the results of a change in the management strategy of the driveline and the resultant significant decrease in DLls observed at our institution.

\section{Methods}

After obtaining IRB approval, we retrospectively reviewed medical records for all patients that received a left ventricular assist device from 9/1/2010 to 5/30/2015 at our institution. The IRB determined that informed consent was not required. We abstracted data regarding the indication for device placement, INTERMACS profile, baseline demographics, driveline management protocol, development of driveline infection and its microbiology, post-operative complications, length of hospital stay, duration of follow-up, and mortality. INTERMACS profile is a marker of severity of heart failure and ranges from 1-7; profile 1 is critical cardiogenic shock and profile 7 is consistent with advanced New York Heart Association functional class III heart failure.(9) We excluded all other infections such as VAD pump infection, mediastinitis, bloodstream infection, pneumonia, urinary tract infection etc.

Definition of DLI: We used the standardized definitions put forth by the International Society of Heart and Lung Transplantation (ISHLT) in 2011.(10) Briefly, findings on surgery (if performed), growth of an organism on aseptic culture, clinical signs/ symptoms, and wound appearance are combined to define a superficial or deep DLI. For purposes of our study, we combined superficial and deep DLI into one category.

VAD surgery: During the study period, our center implanted two types of durable continuous flow ventricular assist devices - HeartMate II (Thoratec Corporation, Pleasanton, CA) and HeartWare HVAD system (HeartWare, Framingham, MA). Two main cardiothoracic surgeons performed the surgeries according to established surgical technique. The driveline was tunneled in the subcutaneous tissue with the exit site generally on the right abdominal wall. The velour portion of the driveline was consistently placed under the skin in all patients.

Perioperative antibiotic prophylaxis consisted of vancomycin and cefepime that was started within one hour prior to surgical incision and continued for 48 hours thereafter. Prior to $9 / 2012$, we used cefazolin as peri-operative prophylaxis, which was continued for 48 hours post-operatively as well.

Driveline Management Protocol: We compared two non-concurrent cohorts of patients based on their driveline management protocol.

Group 1- The driveline dressing change occurred daily and consisted of chlorhexidine cleansing (ChloraPrep $®$ One-Step, CareFusion, USA) and sterile $4 \times 4$ gauze followed by the placement of an abdominal binder. This was the management protocol for patients that underwent VAD implantation from $9 / 1 / 2010$ to $8 / 31 / 2012$.

Group 2 - The driveline dressing changes were done every 3 days and consisted of chlorhexidine cleansing (ChloraPrep ${ }^{\circledR}$ One-Step, CareFusion, USA), silver- 
impregnated foam (Mepilex® Ag, Molnlycke Healthcare Sweden) which was then covered by a clear dressing (Centurion $\AA$ Sorbaview ${ }^{\circledR}$ Shield, Centurion Medical Products Corp, USA) and placement of an "anchor" (Centurion ${ }^{\circledR}$ Foley Anchor, Centurion Medical Products Corp, USA) to prevent excess driveline movement (instead of the abdominal binder). This management protocol went into effect from $9 / 1 / 2012$ to the current time.

Patients and families were instructed on how to care for the driveline at home prior to hospital discharge and this teaching was reiterated at clinic visits by the VAD coordinators. If patients developed redness, pain, drainage from the driveline and/ or fever or other symptoms consistent with sepsis, they were thoroughly evaluated to look for a source of infection and possible VAD involvement. This work-up included blood cultures, aseptic culture of drainage from the driveline (if applicable) and imaging (echocardiogram/ computed tomography scan and/ or ultrasound).

We censored follow-up at the occurrence of first driveline infection, removal of the device, transplantation or death. In addition, follow-up of Group 1 patients was censored at the time the institutional change in dressing protocol occurred; thus Group 1 only includes the time at risk as the time the patient was undergoing the management strategy for Group 1. Figure 1 shows pictures of both types of dressings.

Figure 1. Pictures of the driveline dressing in Group 1 (a) and Group 2 (b).

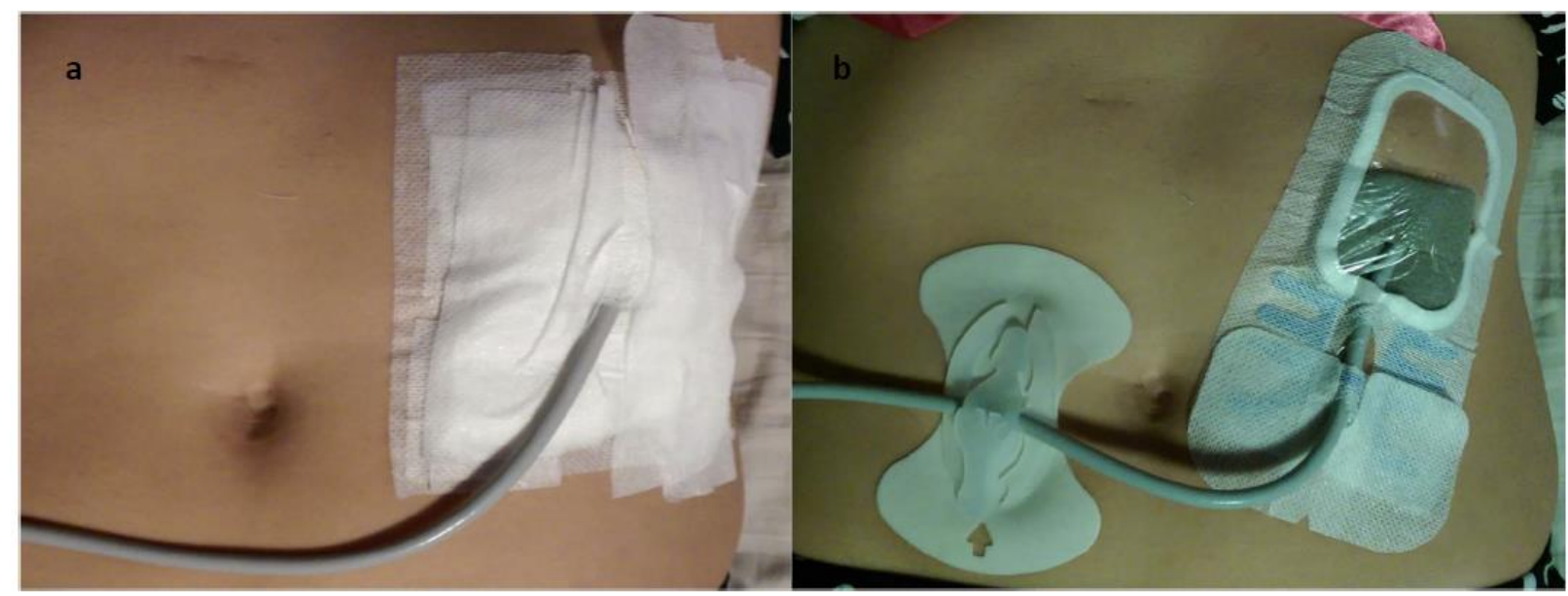

Statistical analysis: Univariate analyses were performed via t test or Fischer's exact test as appropriate. Logistic regression was performed for multivariate analysis of factors that were associated with development of DLI in univariate analysis. Kaplan-Meier survival analysis was used for estimating freedom from first DLI. Log-rank test was used to compare infection-free survival differences among groups. Patients who did not experience DLI were censored if they died, were transplanted, explanted for recovery, or lost to follow-up. We used Stata (Statacorp, College Station, Texas) as the software for analysis. 


\section{Results}

During the study period, 88 patients underwent left VAD placement (64 HeartMate II, 24 HeartWare HVAD). Of these, 5 patients underwent device exchange for device thrombosis (4 HeartMate II, 1 HeartWare HVAD) and 7 patients had concurrent right VADs (7 HeartWare HVAD). There were 24 patients in Group 1 and 64 patients in Group 2.

Baseline characteristics at the time of VAD implantation are detailed in Table 1, including demographics, INTERMACS profile, underlying cardiomyopathy, other co-morbidities, basic laboratory parameters, and length of initial hospitalization at which the device was placed. The main differences between the two groups were in the indication for VAD implantation (Group 1 had $75 \%$ of DT patients vs. 46.9\% in Group 2, $p=0.029$ ), the type of device (Group 1 had 100\% HeartMate II vs. $62.5 \%$ in Group 2, p<0.0001) and INTERMACS category (Group 1 had $8.3 \%$ INTERMACS category 4 vs. $31.3 \%$ in Group 2, $p=0.029)$. Other parameters, including age, race, sex, underlying cardiac disease, co-morbidities, need for hemodialysis, length of hospitalization at index surgery, and return to the operating room were similar in both groups.

Table 1. Baseline demographics of the study population.

Group 1 patients underwent daily driveline dressing change consisting of chlorhexidine cleansing and sterile $4 \times 4$ gauze followed by the placement of an abdominal binder. Group 2 patients underwent driveline dressing changes every 3 days consisting of chlorhexidine cleansing followed by a non-sterile silverimpregnated dressing which was then covered by a clear dressing, and placement of an "anchor" to prevent excess driveline movement (instead of the abdominal binder).

\begin{tabular}{llll}
\hline & $\begin{array}{l}\text { Group 1 } \\
(\mathrm{n}=24)\end{array}$ & $\begin{array}{l}\text { Group 2 } \\
(\mathrm{n}=64)\end{array}$ & p-value \\
\hline $\begin{array}{l}\text { Age in years, mean } \\
\text { (SD) }\end{array}$ & $58.25(14.9)$ & $58.2(14)$ & $\mathrm{NS}$ \\
\hline Male sex (\%age) & $17(70.8 \%)$ & $54(84.4 \%)$ & $\mathrm{NS}$ \\
\hline $\begin{array}{l}\text { Race (\%age) } \\
\text { Caucasian }\end{array}$ & $18(75 \%)$ & $31(48.4 \%)$ & $\mathrm{NS}$ \\
$\begin{array}{l}\text { African-American } \\
\text { Asian }\end{array}$ & $3(12.5 \%)$ & $12(18.8 \%)$ & \\
Other & $2(8.3 \%)$ & $5(7.8 \%)$ & \\
& $1(4.2 \%)$ & $16(25 \%)$ & \\
\hline Hispanic ethnicity & $4(16.7 \%)$ & $16(25 \%)$ & $\mathrm{NS}$ \\
(\%age) & & & \\
\hline INTERMACS profile at & & & \\
time of implantation & & & \\
1 & $4(16.7 \%)$ & $18(28.1 \%)$ & \\
2 & $12(50 \%)$ & $14(21.9 \%)$ & \\
3 & $6(25 \%)$ & $12(18.8 \%)$ & \\
4 & $2(8.3 \%)$ & $20(31.3 \%)$ & \\
\hline
\end{tabular}




\begin{tabular}{|c|c|c|c|}
\hline $\begin{array}{l}\text { Indication } \\
\text { Bridge to transplant } \\
\text { Destination therapy }\end{array}$ & $\begin{array}{l}6(25 \%) \\
18(75 \%)\end{array}$ & $\begin{array}{l}34(53.1 \%) \\
30(46.9 \%)\end{array}$ & 0.029 \\
\hline $\begin{array}{l}\text { Type of VAD } \\
\text { HeartMate II } \\
\text { HeartWare }\end{array}$ & $\begin{array}{l}24(100 \%) \\
0\end{array}$ & $\begin{array}{l}40(62.5 \%) \\
24(37.5 \%)\end{array}$ & $<0.0001$ \\
\hline $\begin{array}{l}\text { Primary disease } \\
\text { Ischemic } \\
\text { Non-ischemic }\end{array}$ & $\begin{array}{l}11(45.8 \%) \\
13(54.2 \%)\end{array}$ & $\begin{array}{l}25(39.1 \%) \\
39(60.9 \%)\end{array}$ & NS \\
\hline $\begin{array}{l}\text { Co-morbidities at time of } \\
\text { VAD placement } \\
\text { Diabetes } \\
\text { CVA } \\
\text { Cirrhosis } \\
\text { COPD }\end{array}$ & $\begin{array}{l}7(29.2 \%) \\
0 \\
0 \\
2(8.3 \%)\end{array}$ & $\begin{array}{l}27(42.2 \%) \\
4(6.3 \%) \\
10(15.6 \%) \\
11(17.2 \%)\end{array}$ & $\begin{array}{l}\text { NS } \\
\text { NS } \\
\text { NS } \\
\text { NS }\end{array}$ \\
\hline $\begin{array}{l}\text { Body Mass Index, mean } \\
\text { (SD) }\end{array}$ & $26.6(4.3)$ & $26(0.7)$ & NS \\
\hline $\begin{array}{l}\text { Baseline laboratory } \\
\text { parameters (with SD) }\end{array}$ & & & \\
\hline $\begin{array}{l}\text { Sodium, } \mathrm{mmol} / \mathrm{L} \\
\text { Creatinine, } \mathrm{mg} / \mathrm{dL} \\
\text { WBC, } 10^{3} / \mathrm{mm}^{3} \\
\text { HCT, } \% \\
\text { Platelets, } 10^{3} / \mathrm{mm}^{3} \\
\text { Bilirubin, } \mathrm{mg} / \mathrm{dL} \\
\text { Albumin, } \mathrm{g} / \mathrm{dL} \\
\text { INR } \\
\text { HbA1c }\end{array}$ & $\begin{array}{l}133(5.7) \\
1.4(0.5) \\
8.8(3.5) \\
34.5(5.3) \\
205.5(53.7) \\
1.5(1.4) \\
3.7(0.4) \\
1.3(0.3) \\
6.2(0.6)\end{array}$ & $\begin{array}{l}132.8(6.7) \\
1.4(0.48) \\
8.6(3.8) \\
32.5(5.4) \\
199(84.3) \\
1.4(1.3) \\
3.6(0.6) \\
1.5(0.4) \\
6.2(0.6)\end{array}$ & $\begin{array}{l}\text { NS } \\
\text { NS } \\
\text { NS } \\
\text { NS } \\
\text { NS } \\
\text { NS } \\
\text { NS } \\
\text { NS } \\
\text { NS }\end{array}$ \\
\hline $\begin{array}{l}\text { Post-VAD dialysis } \\
\text { during index } \\
\text { hospitalization }\end{array}$ & $3(12.5 \%)$ & $5(7.8 \%)$ & NS \\
\hline $\begin{array}{l}\text { Mean length of index } \\
\text { hospitalization in days, } \\
\text { (SD) }\end{array}$ & $35.9(35)$ & $44.3(50.3)$ & NS \\
\hline $\begin{array}{l}\text { Previous cardiac } \\
\text { surgery }\end{array}$ & $11(45.8 \%)$ & $17(26.6 \%)$ & NS \\
\hline $\begin{array}{l}\text { Return to operating } \\
\text { room within } 30 \text { days of } \\
\text { index surgery }\end{array}$ & $4(16.7 \%)$ & $5(7.8 \%)$ & NS \\
\hline
\end{tabular}

*INTERMACS profile 1 - critical cardiogenic shock; INTERMACS profile 2 progressive decline in heart failure despite intravenous inotropic support; INTERMACS profile 3- stable heart failure but dependent on intravenous inotropic support; INTEMACS profile 4- resting heart failure symptoms but without intravenous inotropic support.

Driveline Infections: As seen in Table 2, the change in driveline management protocol resulted in a significant reduction in driveline infections in Group 2 vs. Group 1 (6.3\% vs. $41.7 \%, \mathrm{p}<0.0001)$ along with a significant decrease in the incidence of DLI/ 1000 device days; 0.24 vs. $1.81, p=0.0002$. Kaplan-Meier 
survival curves (Figure 2) demonstrated significantly increased infection-free survival in Group 2 patients; log-rank test, $p=0.0003$. The mean onset of DLI in group 1 was 217.1 days vs 74.8 days in Group 2; this was not statistically significant $(\mathrm{p}=0.12)$.

The overall mortality rate during the time of device placement was $11.4 \%(n=10)$ and was unrelated to the development of a DLI. The relative risk reduction due to the new driveline management protocol was $85 \%$ and the number needed to treat was 2.82.

Table 2. Occurrence of driveline infections (DLI) in the two cohorts of patients.

\begin{tabular}{llll}
\hline & Group 1 $(\mathrm{n}=24)$ & Group 2 $(\mathrm{n}=64)$ & $\mathrm{p}$-value \\
\hline $\begin{array}{l}\text { No. of driveline } \\
\text { infections }\end{array}$ & $10(41.7 \%)$ & $4(6.3 \%)$ & $<0.0001$ \\
\hline $\begin{array}{l}\text { Days of device follow- } \\
\text { up, mean (SD) * }\end{array}$ & $230.8(195.3)$ & $258.2(232.5)$ & 0.61 \\
\hline $\begin{array}{l}\text { DLI incidence/ 1000 } \\
\text { device days }\end{array}$ & 1.81 & 0.24 & 0.0002 \\
\hline $\begin{array}{l}\text { DLI incidence/ } 100 \\
\text { patient years }\end{array}$ & 65.9 & 8.8 & 0.0002 \\
\hline *ensored at protocol change, device removal/transplant, death or DLI
\end{tabular}

Figure 2. Kaplan-Meier estimates for freedom from driveline infection for the two cohorts of patients undergoing different driveline management protocols; log-rank test, $\mathrm{p}=0.0003$

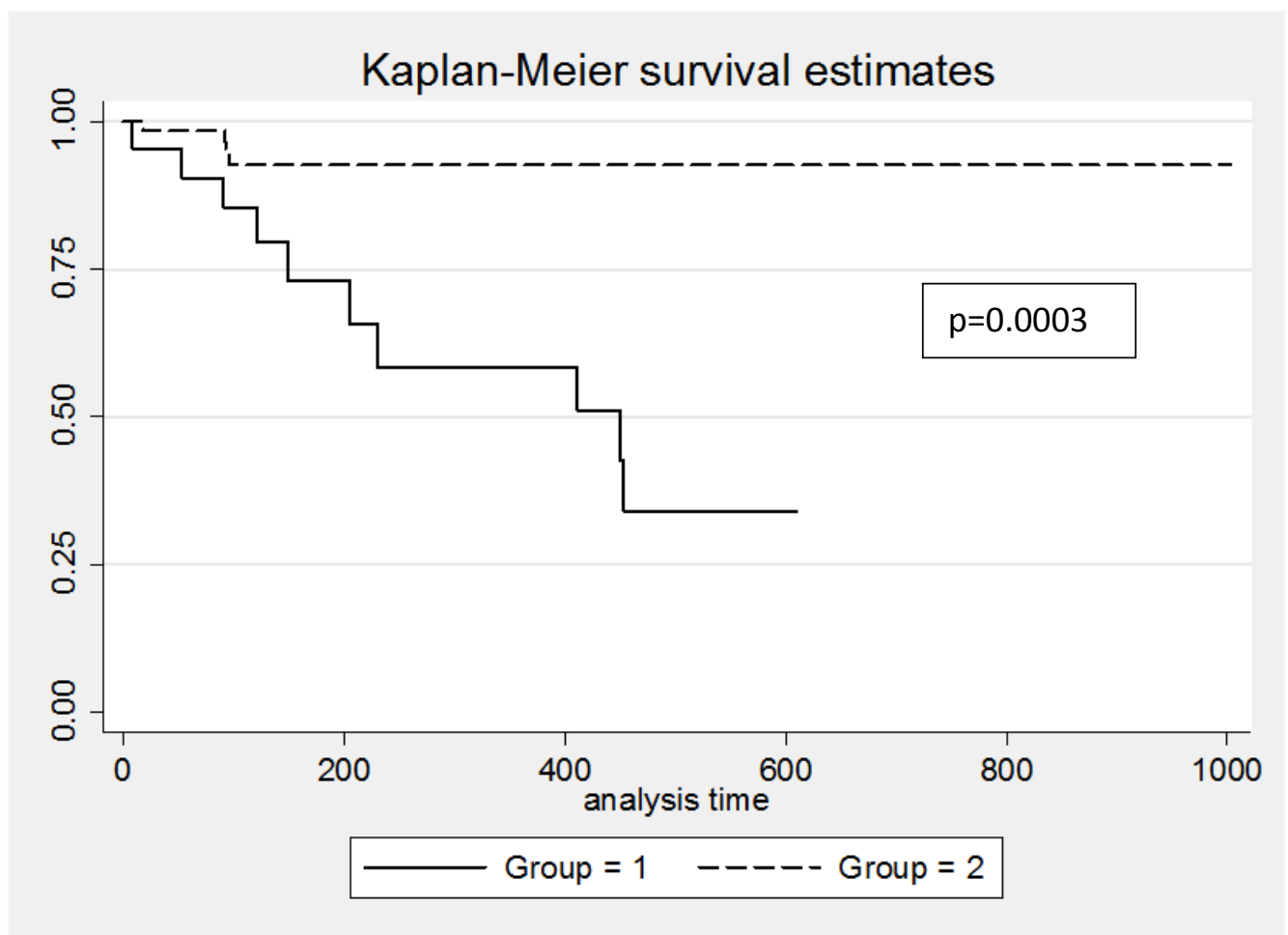


We also analyzed the rate of DLI, incidence of $D L I / 1000$ device days as well as log-rank survival analysis in the indication for transplant i.e. BTT vs. DT patients (no statistical difference) and the type of device implanted i.e. HeartMate II vs. HeartWare patients (no statistical difference). These results are shown in the Appendix Tables 1 and 2. We also conducted a sensitivity analysis of DLI occurrence including the indication for device implant as well as the type of device used assuming a potential 10\% misclassification error and specificity of $90 \%$. In this sensitivity analysis, the only significant predictor of the outcome of DLI was the Group assignment (OR 0.00085, 95\% 7.29e-07- 0.99294; $p=0.05$ though a $95 \% \mathrm{Cl}$ that did not cross 1 ).

Risk factors for development of DLI: In univariate analysis, patient presence in Group 2 was significantly lower in patients with a DLI (28.6\% among patients with a DLI vs. $81.1 \%$ in those without a DLI, $p<0.0001$ ). There was a trend towards higher body mass index (BMI) in patients with DLIs vs. those that did not develop a DLI (mean BMI 28.62 vs. 25.6, $p=0.059$ ). We did not find an association with age, indication for VAD placement, INTERMACS category, device type, underlying cardiac disease, length of initial hospital stay, various co-morbidities including diabetes mellitus, post-operative need for hemodialysis, previous cardiac surgery or return to the operating room within 30 days of VAD placement. Baseline laboratory parameters at the time of VAD implantation including serum sodium, creatinine, white blood cell count, platelets, bilirubin, and albumin were similar in patients that developed DLI and those that did not. Patients that developed DLI had a higher hematocrit (mean 36.6 vs. 32.4, $\mathrm{p}=0.008$ ) and lower INR (1.23 vs. $1.47 ; p=0.048$ ) than those that did not develop a DLI in univariate analysis.

The multivariate model included the driveline management group, BMI, hematocrit and INR; only the driveline management strategy was associated with development of DLI (OR 0.09, 95\% $\mathrm{Cl} 0.02-0.4, \mathrm{p}=0.002$ ) as shown in Table 3.

Table 3. Univariate and multivariate analysis of factors associated with development of a driveline infection as the outcome (vs. no DLI)

\begin{tabular}{|c|c|c|c|c|c|}
\hline & \multicolumn{2}{|c|}{ Univariate analysis } & \multicolumn{3}{|c|}{ Multivariate analysis } \\
\hline & & $p$-value & $\begin{array}{l}\text { Odds } \\
\text { ratio }\end{array}$ & $\begin{array}{l}95 \% \\
\text { confidence } \\
\text { interval }\end{array}$ & $p$-value \\
\hline $\begin{array}{l}\text { Placement in } \\
\text { Group } 2\end{array}$ & $\begin{array}{l}28.6 \% \\
\text { vs. } \\
81.1 \%\end{array}$ & $<0.0001$ & 0.09 & $0.02-0.4$ & 0.002 \\
\hline BMI (mean) & $\begin{array}{l}28.6 \text { vs. } \\
25.6\end{array}$ & 0.059 & & & NS \\
\hline $\begin{array}{l}\mathrm{HCT}, \% \\
\text { (mean) }\end{array}$ & $\begin{array}{l}36.6 \text { vs. } \\
32.4\end{array}$ & 0.008 & & & NS \\
\hline INR & $\begin{array}{l}1.23 \text { vs. } \\
1.47\end{array}$ & 0.047 & & & NS \\
\hline
\end{tabular}


We constructed an additional multivariate model including the driveline management group, indication for transplant, and type of device. Again, only the driveline management strategy was independently associated with DLI (OR 0.1 , $95 \% \mathrm{Cl} 0.03-0.5, \mathrm{p}=0.003$ ) and the indication for device placement (i.e. BTT, DT) as well as type of device placed were not associated with DLI.

Microbiology: The majority of infections were caused by staphylococcal species. Microbiology of infections was as follows - methicillin-sensitive Staphylococcus aureus (6), methicillin-resistant $S$. aureus (2), coagulase-negative staphylococci (3), one with concurrent Propionibacterium acnes, Streptococcus viridans (1), Enterobacter cloacae (1), and no culture done (1).

Clinical Outcome of DLI: Among all patients with DLI, concurrent pocket infection was present in 3, pump/cannula infection manifested as persistent bacteremia was present in 3 , and concurrent mediastinitis in 2 . Eight patients underwent surgical debridement and three required a device exchange secondary to infection. Majority of the patients were treated with 6-8 weeks of intravenous antibiotics, though 2 patients required IV antibiotics for $>12$ weeks, followed by varying lengths of oral suppression. Among the 14 patients with DLI, six (all were in Group 1) developed recurrent or new infection with a different organism often while still on suppressive antibiotics for their first infection. Three patients required device exchange for thrombosis following the onset of DLI. Five patients underwent successful heart transplantation following DLI onset.

\section{Discussion}

Percutaneous driveline infections are associated with significant morbidity and mortality, which is especially important since an increasing number of patients are now receiving VADs for long-term destination therapy. Driveline infection and bloodstream infections in VAD recipients has been associated with neurologic complications including cerebrovascular accidents.(11-13) Additionally, antecedent infection was noted in a third of VAD recipients prior to the development of device thrombosis and/or hemolysis.(14) Thus, device infection appears to be associated with greater downstream problems in addition to the already significant morbidity associated with device infection alone (including hospital readmission, long courses of intravenous antibiotics, patient discomfort, decreased quality of life, as well as repeat surgery). Despite all these issues and the fact that over 15,000 VADS have been implanted worldwide,(15) there is no consensus on the optimal driveline management protocol, as evidenced by a recent US survey of VAD centers.(7)

Driveline management consists of driveline stabilization as well as the exit site cleansing and dressing. In this study, we demonstrated a significant decrease in DLI in our VAD population by a change in driveline management strategy. We demonstrated a decrease in DLIs from 1.81 to 0.24 events/ 1000 device days, which corresponds to a relative risk reduction of $85 \%$ and a number needed to treat of 2.82 . 
Silver sulfadiazine, along with chlorhexidine and triclosan, impregnated VAD driveline has been shown to decrease bacterial colonization in vivo.(16) The group from Columbia reported results from their use of a sterile silver gauze driveline dressing (SILVERCEL, Non-Adherent Antimicrobial Alginate Dressing) along with a Foley anchor device for driveline stabilization and also demonstrated a significant decrease in DLI with a relative risk reduction of $62.5 \%$.(17) Of note, our new dressing change protocol did not include sterile technique, yet was associated with significantly fewer infections than our previous technique or published data among VAD centers. This is important as adding sterile technique increases both cost and complexity of dressing changes.

Traditionally an abdominal binder has been used to stabilize the driveline, despite the fact that it is frequently cumbersome and uncomfortable to use, potentially leading to decreased outpatient compliance as communicated by some of our patients. In our updated driveline management strategy, use of a small anchor made it easier for patients to use at home and potentially ensured better compliance, though we did not specifically assess compliance in this retrospective study. Additionally, decreasing the frequency of dressing changes to every 3 days decreased the physical manipulation of the site with decreased risk of introduction of infection.

There are currently several approaches to minimizing driveline infections. These can be broadly categorized under surgical approaches, peri-operative antibiotic prophylaxis regimens, and approach to the driveline exit site management. The Driveline Silicone Interface Registry study demonstrated increased freedom from DLI in subjects implanted with a HeartMate II VAD in whom only the silicone portion of the DL was externalized; this is the approach used at our center consistently.(18) Results from the RESIST study were recently published in abstract form and showed ease of use and increased driveline stability with the use of a combination dressing kit that consisted of a proprietary "infection mitigation patch", a clear dressing, tape and driveline anchor that was used specifically for patients with HeartMate II devices; additionally driveline dressing was changed almost weekly. (19) Unfortunately, there has not been a consensus approach to this process as of yet. We believe that reporting of individual studies should lead to larger multicenter trials to determine the optimal driveline management strategy.

There are certain limitations inherent in our retrospective study design. The time periods of Groups 1 and 2 are not concurrent and thus there is a potential that the decreased rate of DLI could be related to an "era effect" due to our center's increasing comfort level with the devices. However, the main surgeons performing the procedure did not change in this time period and the operative approach remained similar as well. Pre- and post-operative management did not change. An additional possibility is that with the change in driveline management protocol, there may have been increased focus on the driveline with potential change in compliance as well as individual technique; however we are unable to measure this from chart review alone. We made several driveline management changes at the same time and hence the effect of each individual change on its own is difficult to gauge. However, similar to the "bundle" effect in decreasing the 
rates of infection in intravascular catheters, we demonstrate that the bundle of changes implemented led to a significant decrease in both the overall rate of infections as well as the incidence of driveline infections/ 1000 device days.

In conclusion, there is a need for multicenter studies evaluating various aspects of driveline management including stabilization device, type of dressing and change frequency, as well as cleansing agent. We believe that this study provides important information that may be used to devise such a multicenter trial to determine the optimal driveline management strategy for VAD recipients.

\section{References}

1. Heart Failure Fact Sheet|Data \& Statistics|DHDSP|CDC. 2014.

2. Kirklin JK, Naftel DC, Pagani FD, et al.: Sixth INTERMACS annual report: a 10,000-patient database. The Journal of heart and lung transplantation : the official publication of the International Society for Heart Transplantation 2014;33:555-64.

3. Pereda D, Conte JV: Left ventricular assist device driveline infections. Cardiology clinics 2011;29:515-27.

4. Zierer A, Melby SJ, Voeller RK, et al.: Late-onset driveline infections: the Achilles' heel of prolonged left ventricular assist device support. The Annals of thoracic surgery 2007;84:515-20.

5. Raymond AL, Kfoury AG, Bishop CJ, et al.: Obesity and left ventricular assist device driveline exit site infection. ASAIO J 2010;56:57-60.

6. Goldstein DJ, Naftel D, Holman W, et al.: Continuous-flow devices and percutaneous site infections: clinical outcomes. The Journal of heart and lung transplantation : the official publication of the International Society for Heart Transplantation 2012;31:1151-7.

7. Cannon A, Elliott T, Ballew $\mathrm{C}$, et al.: Variability in infection control measures for the percutaneous lead among programs implanting long-term ventricular assist devices in the United States. Prog Transplant 2012;22:351-9.

8. Baronetto A, Centofanti $P$, Attisani M, et al.: A simple device to secure ventricular assist device driveline and prevent exit-site infection. Interactive cardiovascular and thoracic surgery 2014;18:415-7.

9. Stevenson LW, Pagani FD, Young JB, et al.: INTERMACS profiles of advanced heart failure: the current picture. The Journal of heart and lung transplantation : the official publication of the International Society for Heart Transplantation 2009;28:535-41.

10. Hannan MM, Husain S, Mattner F, et al.: Working formulation for the standardization of definitions of infections in patients using ventricular assist devices. The Journal of heart and lung transplantation : the official publication of the International Society for Heart Transplantation 2011;30:375-84.

11. Nakajima I, Kato TS, Komamura K, et al.: Pre- and post-operative risk factors associated with cerebrovascular accidents in patients supported by left ventricular assist device. -Single center's experience in japan. Circulation journal : official journal of the Japanese Circulation Society 2011;75:1138-46. 
12. Kato TS, Schulze PC, Yang J, et al.: Pre-operative and post-operative risk factors associated with neurologic complications in patients with advanced heart failure supported by a left ventricular assist device. The Journal of heart and lung transplantation : the official publication of the International Society for Heart Transplantation 2012;31:1-8.

13. Aggarwal A, Gupta A, Kumar S, et al.: Are blood stream infections associated with an increased risk of hemorrhagic stroke in patients with a left ventricular assist device? ASAIO J 2012;58:509-13.

14. Whitson BA, Eckman P, Kamdar F, et al.: Hemolysis, pump thrombus, and neurologic events in continuous-flow left ventricular assist device recipients. The Annals of thoracic surgery 2014;97:2097-103.

15. Kirklin JK, Naftel DC, Pagani FD, et al.: Seventh INTERMACS annual report: 15,000 patients and counting. The Journal of heart and lung transplantation : the official publication of the International Society for Heart Transplantation 2015.

16. Choi L, Choudhri AF, Pillarisetty VG, et al.: Development of an infectionresistant LVAD driveline: a novel approach to the prevention of device-related infections. The Journal of heart and lung transplantation : the official publication of the International Society for Heart Transplantation 1999;18:1103-10.

17. Cagliostro B, Levin AP, Fried J, et al.: Continuous-flow left ventricular assist devices and usefulness of a standardized strategy to reduce drive-line infections. The Journal of heart and lung transplantation : the official publication of the International Society for Heart Transplantation 2015.

18. D. Dean GAE, A. Tatooles, B.C. Sheridan, R.J. Brewer, C. Caldeira, F. Kallel, D.J. Farrar, S.A. Akhter: Reduction in Driveline Infection Rates: Results from the HeartMate II Multicenter Silicone-Skin-Interface (SSI) Registry. The Journal of Heart and Lung Transplantation 2014;33:S11-S2.

19. Thoratec's Reduce Driveline Trauma Through Stabilization and Exit Site Management Study (RESIST).

Appendix Table 1. Occurrence of driveline infections (DLI) in the bridge to transplant (BTT) vs destination therapy (DT) groups of patients. Follow-up censored at protocol change, device removal/transplant, death or DLI

\begin{tabular}{llll}
\hline & BTT $(\mathbf{n}=40)$ & DT $(\mathbf{n}=48)$ & p-value \\
\hline $\begin{array}{l}\text { No. of driveline } \\
\text { infections }\end{array}$ & $4(10 \%)$ & $10(20.8 \%)$ & 0.24 \\
\hline $\begin{array}{l}\text { DLI incidence/ } 1000 \\
\text { device days }\end{array}$ & 0.52 & 0.7 & 0.32 \\
\hline $\begin{array}{l}\text { DLI incidence/ 100 } \\
\text { patient years }\end{array}$ & 18.9 & 25.5 & 0.32 \\
\hline $\begin{array}{l}\text { Log-rank for infection- } \\
\text { free survival analysis }\end{array}$ & & 0.52 \\
\hline
\end{tabular}


Appendix Table 2. Occurrence of driveline infections (DLI) based on the type of device implanted (HeartMate II vs HeartWare). Follow-up censored at protocol change, device removal/transplant, death or DLI

\begin{tabular}{llll}
\hline & $\begin{array}{l}\text { HeartMate II } \\
(\mathbf{n = 6 4 )}\end{array}$ & $\begin{array}{l}\text { HeartWare } \\
(\mathbf{n = 2 4 )}\end{array}$ & p-value \\
\hline $\begin{array}{l}\text { No. of driveline } \\
\text { infections }\end{array}$ & $13(20.3 \%)$ & $1(4.2 \%)$ & 0.1 \\
\hline $\begin{array}{l}\text { DLI incidence/ } 1000 \\
\text { device days }\end{array}$ & 0.74 & 0.23 & 0.12 \\
\hline $\begin{array}{l}\text { DLI incidence/ } 100 \\
\text { patient years }\end{array}$ & 26.8 & 8.3 & 0.12 \\
\hline $\begin{array}{l}\text { Log-rank for infection- } \\
\text { free survival analysis }\end{array}$ & & 1.64 \\
\hline
\end{tabular}

